\title{
Counseling Advocacy Competencies in Action: Lessons Learned through the See the Triumph Campaign
}

\author{
Christine E. Murray \\ The University of North Carolina at Greensboro
}

\author{
Allison Crowe \\ East Carolina University
}

\begin{abstract}
With the growing emphasis on social justice in the counseling and psychology professions, mental health professionals are increasingly called upon to engage in advocacy work. In this article, the authors describe their advocacy campaign, See the Triumph, which aims to end the stigma surrounding intimate partner violence. See the Triumph is based on research with survivors of intimate partner violence, whose stories inspired the development of the campaign. The article describes how the See the Triumph campaign reflects the American Counseling Association's Advocacy Competencies, as well as the most significant lessons learned through the campaign.
\end{abstract}

Keywords: advocacy competencies, intimate partner violence, stigma, social justice

With the growing emphasis on social justice in the profession, mental health professionals are increasingly called upon to engage in advocacy work (Steele, 2008; Toporek, Lewis, \& Crethar, 2009). Advocacy is defined as "the act of taking action to produce environmental change on behalf of clients and is considered a framework to help clarify how counselors can practice social justice" (Steele, p. 75). In 2003, the American Counseling Association's (ACA) Governing Council endorsed a comprehensive set of Advocacy Competencies (Lewis, Arnold, House, \& Toporek, 2002). Although advocacy has been a growing focus of other disciplines within the mental health field, the primary focus of the current article is on counseling, although the topics discussed hold relevant for mental health professionals in any discipline who are interested in advocacy and social justice work.

The ACA's Competencies (Lewis et al., 2002) put forth 43 specific behavioral competencies to guide counselors' activities when engaging in advocacy work, and they address actions that may be taken across three levels of intervention - the client or student, the school or community, and the public. 
Each level can be conceptualized as ranging from the micro level (client or student) to the macro level (public arena). Additionally, advocacy efforts can be understood as acting with as well as acting on behalf. For example, at the client or student level, the advocacy-oriented counselor might consider empowerment (acting with), as well as client or student advocacy (acting on behalf). At the school or community level, the counselor might engage in community collaboration (acting with) or more of systems advocacy (acting on behalf), and in the public arena, a counselor might focus on public information (acting with) or social/political advocacy (acting on behalf).

Even with this growing attention to the importance of counselors engaging in advocacy work, many counselors are still learning how to step into the advocacy role (Steele, 2008; Toporek et al., 2009), and counselor education programs often lack significant training to help students develop advocacy skills (Steele). At the present time, there have been limited descriptions of counselors' advocacy initiatives to provide models of the application of the Advocacy Competencies into practice (see Toporek et al.). However, such models of counselors' advocacy efforts are valuable for illustrating the challenges and opportunities that can arise when engaging in this work. Previous authors (Toporek et al.) offered examples of how to implement ACA's Advocacy Competencies through case studies. Our goal in this article is to add to this small body of literature by describing an ongoing advocacy initiative, which was co-founded by two counselor educators in CACREP-accredited training programs. We explain how the initiative aligns with ACA advocacy competencies as a way to provide a concrete example to counselors and counselor educators.

The authors of this article are the co-founders of the See the Triumph campaign, which aims to end the stigma surrounding intimate partner violence (IPV) (http://www.seethetriumph.org). The See the Triumph campaign provides an example of a research project that evolved from data collection, to interpretation, to dissemination, and finally into an advocacy initiative that continues to build upon an ongoing program of research. The research studies that provided the empirical and conceptual foundation for the See the Triumph campaign have been published or are currently in press elsewhere, although they will be discussed briefly below. In this article, we discuss the origins, evolution, current status, and future plans for See the Triumph, with a particular focus on how the campaign applies to all of the 43 ACA Advocacy Competencies. Before providing a detailed description of See the Triumph, we briefly review the ACA Advocacy Competencies. The article concludes with some of the most significant lessons we have learned about advocacy, advocacy competencies, and social justice through See the Triumph.

\section{About the See the Triumph Social Media Campaign}

See the Triumph is a research-based social media campaign designed to challenge the stigma surrounding IPV and to provide supportive resources for survivors. See the Triumph can be found on numerous social media platforms, including our website/blog (http://www.seethetriumph.org), Facebook (https://www.facebook.com/seethetriumph), Twitter (https://twitter.com/SeetheTriumph), Pinterest (http://www.pinterest.com/seethetriumph/), Instagram (https://instagram.com/safedating4teens/ß), and Causes (https://www.causes.com/stopstigma). In this section, we review the history and research foundation of See the Triumph, our initial entrée into the social media realm and evolution of the campaign over time, the partnerships we have fostered to strengthen the campaign, and some planned future directions. 


\section{Research Foundation}

Before further discussing the social media components of the campaign, it is important to discuss the research foundation that underlies all of our work on the campaign. Approximately two years prior to the launch of the campaign, we began a research agenda to study the stigma surrounding IPV. This line of research built upon each of our areas of expertise: the first author's primary research agenda focuses on IPV, and the second author focuses on stigma, primarily related to the stigma surrounding mental illness. As we began to discuss opportunities for collaboration, we noted that although there were hints in the existing research that there was a stigma surrounding IPV (e.g., previous research on victim-blaming and negative attributions made toward survivors; Esqueda \& Harrison, 2005; Fitzpatrick, Salgado, Suvak, King, \& King, 2004; Langhinrichsen-Rohling, Shlien-Dellinger, Huss, \& Kramer, 2004; Yamawaki, Ostenson, \& Brown, 2009), at the time we were unable to identify any previous research that had been done to determine the applicability of the conceptualization of stigma to the experiences of IPV survivors. However, we have since learned that other researchers were beginning to examine this phenomenon at the same time as we were (Overstreet \& Quinn, 2013), and we have begun to collaborate on additional research with Overstreet, as will be described later in this article.

Given that this was a new research area, we began with qualitative interviews. We interviewed 12 women in our local communities who had been in past abusive relationships, but who had been out of their relationships for at least two years. Participants ranged in ages from 21 to 68; nine participants were white, two were African American, and one was multiracial. These participants were recruited via e-mail snowball sampling, fliers hung in community locations, and notices in local newsletters. This study used phenomenological methodology, in that our main focus was to learn about their experiences with stigma during and after their abusive relationships, but we also heard from them about how they overcame their abuse and the stigma associated with it. Their stories were compelling, intriguing, and challenging. Much of the abuse they experienced was horrific, but we also began to hear a theme from all of them of the strength and resilience that they demonstrated as they moved forward in their lives following the abuse. In addition, the concept of stigma seemed to resonate deeply with them, as they were able to share numerous specific examples of ways they had been stigmatized throughout their abuse-related experiences.

Because of the small sample, we wanted to see whether the concept of stigma applied to a larger, more geographically diverse sample of survivors. Thus, we embarked on our second study, which involved an electronic survey with an international sample of 219 participants who were included in the initial phase of data analyses. Participants for this second study were recruited through electronic means, including email snowball sampling and social media posts on various domestic violenceoriented social media group pages and discussion boards. The mean age of participants was 39.3 years (SD =10.5), and although both men and women were eligible to participate, most participants (n $=212 ; 96.8 \%$ ) were women. For this electronic survey, we recruited another sample of survivors of past IPV, again who had been out of any abusive relationships for at least two years. On the survey, participants were asked to describe their demographic characteristics, their past experiences with abuse, their stigma-related experiences (e.g., which types of stigma they experienced and the sources 
of that stigma), and their perspectives on the process of overcoming their past abuse. We analyzed the expansive dataset based on participants' responses using both qualitative and quantitative procedures, including a content analysis of participants' statements that they made regarding stigma they experienced from professionals from whom they sought help (Crowe \& Murray, 2015), a cluster analysis to identify themes in participants' experiences of different types of stigma (Murray, Crowe, \& Brinkley, 2015), and a content analysis study to develop a conceptual framework for understanding the sources and components of the stigma surrounding IPV (Murray, Crowe, \& Overstreet, in press).

Across samples, we heard a common theme among many participants that they wanted to be able to help others by sharing their own experiences. For example, consider the following participants' quotes:

- "Hopefully by hearing my story others can come to the realization that there is life after abuse."

- "I am better able to help others in the same situation."

- "Telling my story to others has been one of my biggest parts of healing."

- "I have become outspoken and want to help others."

- "I don't regret that it occurred, but embrace what I can do to help other be free from the stigma of abuse or to avoid it all together."

The more we reflected on the desire shared by survivors to help others, along with the depth of the stories that they shared with us, the more we knew that we had a responsibility to do more with the results of our study what is typically done in academia. Of course, we also have published our findings-based on these original and subsequent studies-with several articles currently published or in the process of publication (e.g., Crowe \& Murray, 2015; Flash, Murray, \& Crowe, in press; Murray, Crowe, \& Akers, in press; Murray, Crowe, \& Brinkley, 2015; Murray, Crowe, \& Overstreet, in press).

However, building on previous research on the gap between research and practice related to IPV (Murray, 2009; Murray, Smith, \& Avent, 2010; Murray \& Welch, 2010), we knew that much of the existing research on the topic is never integrated into practice and is inaccessible to domestic violence service providers. Moreover, we knew that in order to reach the population of IPV survivors that our research participants most wanted to help, we would need to use nontraditional methods to disseminate our research findings. This led us to consider developing a social media campaign, and therein the See the Triumph campaign was born. Ultimately, the campaign was developed to help bridge the gap between research and practice by providing a forum for disseminating our research to three main audiences: survivors of IPV, professionals who work with survivors of IPV, and people in the general population who are interested in supporting friends and family members who have experienced IPV.

\section{From Research to Social Media: Launching and Evolution}

See the Triumph was launched on January 1, 2013, with the following first infographic posted on our blog: 


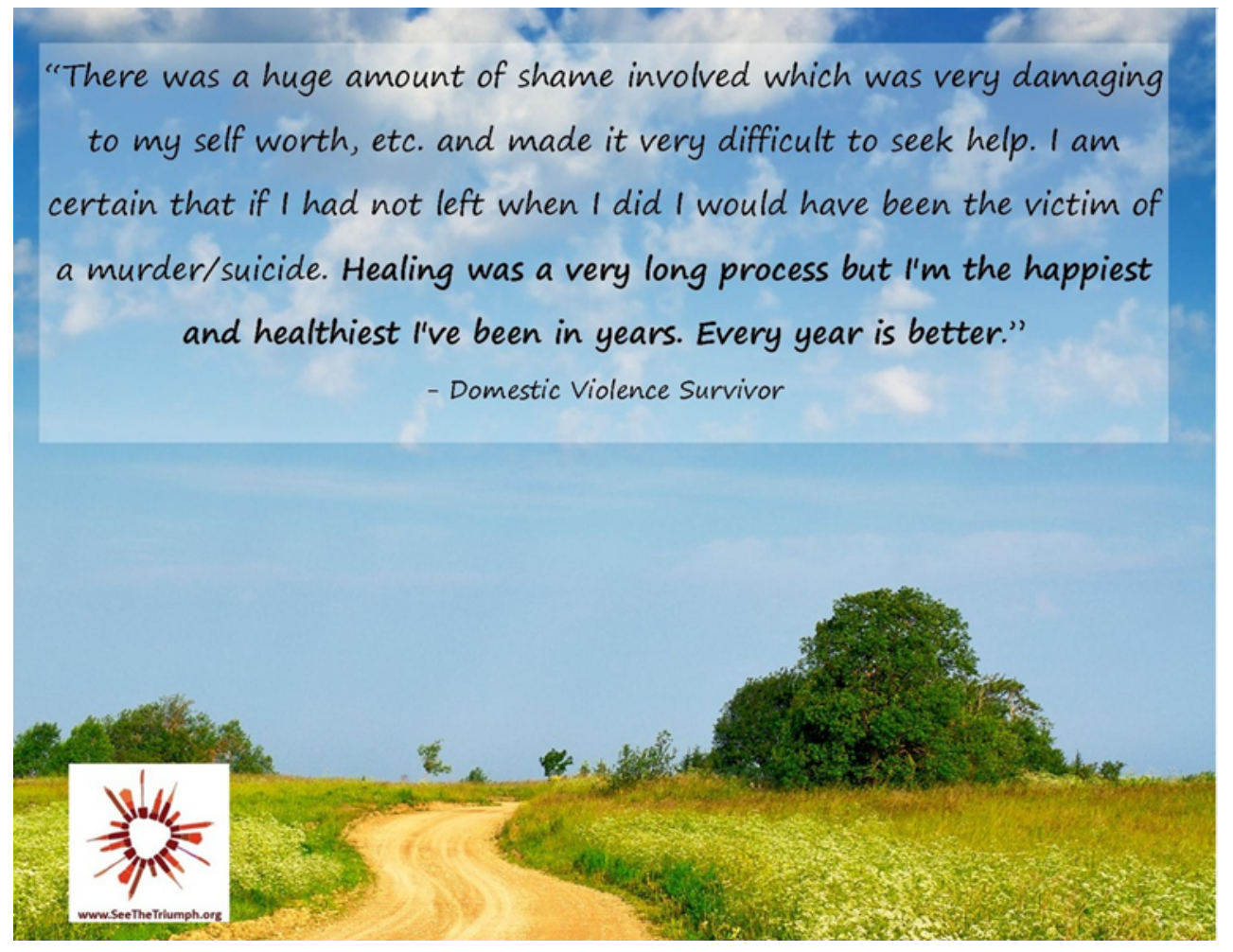

Social media has become an increasingly powerful and important tool for communicating public awareness and public health-related messages to the general and targeted populations. For example, the U.S. Centers for Disease Control and Prevention (2011) note the potential for social media channels to disseminate health information in a time and cost-efficient manner, engage targeted audiences in community-building and interactive dialogues, and help people make safe and healthy choices for their lives. Without funding to support our goals to disseminate our research-based information to survivors, professionals, and the general population, we decided that a social media campaign was a suitable approach for the time and personnel resources we could commit to the initiative. We also examined other social media campaigns targeting survivors of IPV and discovered that these campaigns had the potential to reach our target audience, engage them in a dialogue, and grow a network of people working together to end the stigma surrounding IPV.

As the focus of the current article is on advocacy competencies and not on social media planning, we will only briefly address here some of the major steps we took to plan and launch our campaign. These included: (a) developing a clear set of goals to guide the campaign; (b) identifying an appropriate web-based platform for hosting our website and blog; (c) developing a set of "Terms of Use" for the site to make clear that it is not a forum for providing counseling services and informing users how to use our resources in a safe manner that protects their confidentiality as appropriate; (d) establishing accounts for the campaign on other social media platforms, beginning with Facebook and Twitter; (e) developing content for the blog, which initially focused on infographics using quotes from the survivors who participated in our research (Note: Participants' responses to the surveys were able to be incorporated into the social media campaign because they had completed the surveys anonymously and were informed that their identities would not be revealed in the reporting of the 
results in any manner. All of our research studies have been approved by IRBs at two universities prior to beginning data collection.); and ( $f$ ) developing a schedule to ensure that we would regularly post new content across our various social media platforms. In addition, we needed to identify an appropriate name to capture the mission and focus of our campaign. We wanted a name that reflected the wisdom and insights of our survivors, so we reviewed their survey and interview responses until we had arrived at the following quote:

The only thing that bothers me about it is that other people can't see the triumph in it. Because to me this is a treasure to be at this point in my life, in this stage, and it be beginning. Some people don't even start to realize that they have the issues or start dealing with them until they get to this point.

The notion of "seeing the triumph" captured perfectly our long-term mission for the campaign (i.e., to end the stigma surrounding IPV), as well as the more immediate strategies used to achieve this goal: (a) to share empowering messages that people can overcome their abuse and create positive, nonviolent lives; (b) to describe strategies that have worked for other survivors to help them overcome their abuse and the stigma related to it; and, (c) to promote a new view of battering survivors that shows them as triumphant, courageous, and resourceful.

Initially, growth for the See the Triumph campaign was somewhat slow, which introduced us to the realities of this form of advocacy work. Over time, however, the campaign continued to grow and evolve in meaningful ways. An early partnership with the Stop Abuse Campaign, which will be discussed further in the upcoming Partnerships for Success section, provided us with valuable mentoring in social media marketing, which helped us to increase our focus and grow our reach. We also expanded to other useful social media platforms, including Pinterest and Causes. In particular, Causes provided interactive tools for creating pledges and petitions to promote social action among members of our growing community. For example, we created a Causes pledge to "Tell Survivors: 'It's Not Your Fault,'" which over 1,900 people have taken as of August 9, 2016.

Another important development occurred in October 2013, approximately ten months after the initial launch of See the Triumph. At this point, we began to commit more time and energy to developing more in-depth blog posts. Although we still continue to post infographics with survivors' quotes on them, we have engaged in deeper explorations of topics related to the campaign through blogging, both our own posts and those of our guest bloggers and contributors, which also will be discussed further in the Partnerships for Success section. In 2014, we focused our blogging efforts primarily on a single monthly theme (e.g., teen dating violence, healthy sexuality), and at the end of each month launch a collection of resources on that theme on a designated section of the See the Triumph website (http://www.seethetriumph.org/see-the-triumph-collections.html).

Recent statistics from our various social media platforms demonstrate the growth of the campaign. At the date of this writing (August 9, 2016), our audiences across our various networks include the following: (a) our website/blog has had over 61,000 unique visitors in the past 12 months; (b) our Facebook page has 2,901 likes; (c) our Twitter page has 269 followers; (d) the See the Triumph Causes campaign has 3,501 supporters; (e) our Pinterest page has 884 followers; and (f) our Instagram account 
(i.e., @safedating4teens), which focuses on teen dating violence and was launched during February 2015 for Teen Dating Violence Awareness Month, has 146 followers. Thus, all of our audiences across different social media platforms have shown steady growth over time.

\section{Partnerships for Success}

As the ACA Advocacy Competencies (Lewis et al., 2002) suggest, collaborations are critical to the success of advocacy efforts, and this has been particularly true for the See the Triumph campaign. As noted previously, one of our earliest partnerships was with the Stop Abuse Campaign (http://stopabusecampaign.com/). We initially connected with the Stop Abuse Campaign through a contact of the first author's university colleagues. The Stop Abuse Campaign's founder and President, Andrew Willis, has an impressive career in marketing, and his mentoring was critical to helping us develop our knowledge and skills in these areas. Further, because the Stop Abuse Campaign reached a much broader audience than ours, their support helped to introduce our campaign to a wider network of supporters. Partnering with the Stop Abuse Campaign also provided platforms for crosspostings and re-postings of blogs, as well as other opportunities to communicate about the See the Triumph campaign with broader audiences. Therefore, this partnership was, and continues to be, an instrumental resource to us.

Additional partnerships were fostered through a Delphi study we conducted with an expert panel of leaders of national domestic and sexual violence advocacy organizations (Murray, Crowe, \& Akers, in press). Through Delphi methodology, researchers can identify themes among perspectives of an expert panel on a particular topic, in this case possible strategies for ending the stigma surrounding domestic and sexual violence. This Delphi study was done as part of our ongoing program of research in order to gain an understanding of the stigma surrounding IPV and sexual violence from another important set of key stakeholders in our research and social media efforts. We assumed that leaders of national advocacy organizations had a unique vantage point for understanding the stigma, both as it impacts survivors and as it impacts broader social efforts to prevent and respond to these forms of violence. In addition to publishing the findings of this study in a scholarly journal (Murray, Crowe, \& Akers, in press), a summary of this study was also presented in a See the Triumph blog post: http://www.seethetriumph.org/blog/how-can-we-end-the-stigma-surrounding-domestic-and-sexualviolence-insights-from-a-panel-of-national-experts.

Another significant category of partnerships has come in the form of a growing number of See the Triumph Contributors (i.e., those who develop blog posts or other content on a regular basis) and guest bloggers (i.e., those who contribute only occasionally or on a one-time basis). As of this writing, there are five See the Triumph Contributors, and we have had numerous other guest bloggers share their insights with the campaign. Guest bloggers have shared their insights from their unique work roles and settings (e.g., parent education, conflict resolution, sociology, and advocacy organizations), and they have been especially valuable in helping to provide insights on the topics on which we are developing See the Triumph Collections. Thus, we are able to collaborate with guest bloggers who bring unique areas of expertise to address these topics from their individual vantage points, so that the content found on See the Triumph is interdisciplinary rather than only reflecting a counseling 
perspective. One of the most rewarding aspects of our partnerships with guest bloggers and contributors has been opportunities to involve survivors in telling their stories, whether anonymously or as a named contributor, and we always confirm with these survivors that they believe it is safe for them to share their stories in this way. Therefore, by incorporating the perspectives of survivors through their own stories and voices, we have provided a platform for them to engage in advocacy work themselves, too.

\section{Future Plans}

The See the Triumph campaign continues to grow and evolve. Currently, we are implementing a "Master Plan for Year Three," which involves building the topical collections of resources and strengthening our partnerships with other organizations. Although we continue to have a strong social media focus for the campaign, we have recently begun to work toward face-to-face and "real world" initiatives that will mobilize members of the See the Triumph community to work toward social change and supporting survivors in their local communities. One example of this is the publication of See the Triumph Workbooks, which are designed to be used in support groups or book clubs for survivors to complete in communities with other survivors. Thus, our dual focus moving forward will be to continue to build our social media presence and initiatives and to support social change through face-to-face relationships and actions. These plans are currently under development, but they will be announced via our social media platforms once they are available. Furthermore, the social media initiatives have helped to generate several leads and ideas to further our research on overcoming the stigma surrounding IPV. In addition to our two initial surveys with survivors and the Delphi study described above, we completed a study to develop a conceptual framework for understanding IPVrelated stigma (Murray, Crowe, \& Overstreet, in press), and we are working currently with Overstreet to develop an assessment instrument to provide a reliable and valid measure of the stigma that survivors of IPV face. Finally, as the campaign continues to grow and evolve over time, we will work to conduct a more thorough evaluation of it, moving beyond tracking the numbers of people we reach across our social media platforms to determining the impact of the campaign on reducing the actual stigma surrounding IPV. Thus, overall we view our ongoing research and our social media initiatives as an integrated, multilateral process for understanding and working toward ending the stigma surrounding IPV.

\section{Application of the ACA Advocacy Competencies to See the Triumph}

The See the Triumph campaign encompasses virtually every single one of the ACA Advocacy Competencies (Lewis et al., 2002). Table 1 presents each of the 43 competencies, along with an example of how these competencies are put into action through the See the Triumph campaign. This Table is not intended to be exhaustive, in that we are including only one campaign activity per competency. Readers should note that, in instances in which the ACA Advocacy Competencies refer specifically to clients or students, we apply these competencies by viewing the population of survivors of IPV as a client population, rather than specifically identifying any specific individuals as counseling clients. Further, Murray, King, Crowe, and Flasch (2015) provided an in-depth examination of survivors 
of IPV as advocates for social change, and readers are directed to that article for an expanded discussion of this topic. However, we make clear through the campaign's resources that our audience is not considered to be counseling clients. In fact, our Terms of Use statement on our website/blog makes clear that "No counseling, diagnostic, advice, or assessment services are being or will be provided to anyone through this resource." Nonetheless, as counselors and counselor educators, we view the concept of client empowerment to apply broadly to client populations served by professional counselors. As an additional point of clarification, when we refer to the level of "Community," we similarly define this term broadly, in that counselors and survivors of IPV live within multiple community contexts, based on geography, organizational affiliation, religious and cultural variables, and other factors. Therefore, through the campaign, we incorporate an inclusive definition of the term community to reflect the diversity of communities of which survivors and counselors may be a part.

Table 1. Examples of See the Triumph Campaign Activities and Values that Reflect each ACA Advocacy Competency

\begin{tabular}{|c|c|}
\hline ACA Advocacy Competency & See the Triumph Activity/Value Example \\
\hline \multicolumn{2}{|l|}{ Client/Student Empowerment } \\
\hline $\begin{array}{l}\text { 1. Identify strengths and resources of } \\
\text { clients and students. }\end{array}$ & $\begin{array}{l}\text { Infographics highlight the strengths and triumphs of survivors. Research } \\
\text { questions are designed to highlight participants' personal strengths and } \\
\text { triumphs over past abuse. }\end{array}$ \\
\hline $\begin{array}{l}\text { 2. Identify the social, political, } \\
\text { economic, and cultural factors that } \\
\text { affect the client/student. }\end{array}$ & $\begin{array}{l}\text { Research focuses on identifying and understanding the stigma } \\
\text { surrounding IPV. }\end{array}$ \\
\hline $\begin{array}{l}\text { 3. Recognize the signs indicating that } \\
\text { an individual's behaviors and } \\
\text { concerns reflect responses to } \\
\text { systemic or internalized oppression. }\end{array}$ & $\begin{array}{l}\text { Research findings highlight the common stigma-related experiences } \\
\text { that survivors face, which demonstrates the systemic context of the } \\
\text { stigma. }\end{array}$ \\
\hline $\begin{array}{l}\text { 4. At an appropriate developmental } \\
\text { level, help the individual identify the } \\
\text { external barriers that affect his or her } \\
\text { development. }\end{array}$ & $\begin{array}{l}\text { Infographics and blog posts are written in reader-friendly, non-technical } \\
\text { language. }\end{array}$ \\
\hline $\begin{array}{l}\text { 5. Train students and clients in self- } \\
\text { advocacy skills; } 6 \text {. Help students and } \\
\text { clients develop self-advocacy plans; } \\
\text { and } 7 \text {. Assist students and clients in } \\
\text { carrying out action plans. }\end{array}$ & $\begin{array}{l}\text { Blog posts commonly provide proactive steps and resources that } \\
\text { survivors and others can take and use to advocate within their own } \\
\text { social systems. For example, a Collection on "Everyday Advocacy" } \\
\text { provided a number of resources to help individuals take action in their } \\
\text { communities to promote positive social change to strengthen } \\
\text { community resources to address IPV. }\end{array}$ \\
\hline \multicolumn{2}{|l|}{ Client/Student Advocacy } \\
\hline $\begin{array}{l}\text { 8. Negotiate relevant services and } \\
\text { education systems on behalf of } \\
\text { clients and students. }\end{array}$ & $\begin{array}{l}\text { We address many different ways that the stigma manifests and can be } \\
\text { challenged within, various social systems (e.g., the workplace) and } \\
\text { specific vulnerable populations (e.g., those in violent same-sex } \\
\text { relationships). See the Triumph Collections have been developed to } \\
\text { address stigma surrounding IPV within various social systems, including } \\
\text { churches, schools, and college campuses (See } \\
\text { http://www.seethetriumph.org/see-the-triumph-collections.html). }\end{array}$ \\
\hline $\begin{array}{l}\text { 9. Help clients and students gain } \\
\text { access to needed resources. }\end{array}$ & $\begin{array}{l}\text { We share various resources, such as links to useful information and } \\
\text { training opportunities, through our Facebook page. All resources have } \\
\text { been provided free-of-charge. }\end{array}$ \\
\hline $\begin{array}{l}\text { 10. Identify barriers to the well-being } \\
\text { of individuals and vulnerable groups. }\end{array}$ & $\begin{array}{l}\text { Our blog posts often focus on barriers that survivors of IPV face, such as } \\
\text { victim-blaming. }\end{array}$ \\
\hline
\end{tabular}


11. Develop an initial plan of action for confronting these barriers; 12. Identify potential allies for confronting the barriers; 13. Carry out the plan of action.
We provide tangible steps and offer resources to help community members advocate for themselves. This can be in larger-scale ways (e.g., advocating with their local media) or smaller-scale ways (e.g., sharing a Facebook picture with their own networks to raise awareness about IPV). Thus, we aim to help community members identify problems, identify steps they can take, and carry out those steps in many systems and platforms. For example, a recent series on the blog (http://www.seethetriumph.org/collection-intimate-partner-violencestigma-and-the-media.html) related to addressing irresponsible media reporting that contributes to the stigma surrounding abuse, and this series offered several specific strategies that community members can use to advocate with their local media to address these concerns.

\section{Community Collaboration}

14. Identify environmental factors that impinge upon students' and clients' development. 15. Alert community or school groups with common concerns related to the issue.

16. Develop alliances with groups working for change.

17. Use effective listening skills to gain understanding of the group's goals.

18. Identify the strengths and resources that the group members bring to the process of systemic change.

19. Communicate recognition of and respect for these strengths and resources.

20. Identify and offer the skills that the counselor can bring to the collaboration.

21. Assess the effect of counselor's interaction with the community.

\section{Systems Advocacy}

22. Identify environmental factors impinging on students' or clients' development.

23. Provide and interpret data to show the urgency for change.

24. In collaboration with other stakeholders, develop a vision to guide change.

25 . Analyze the sources of political power and social influence within the system.
Our research findings highlight many environmental factors that survivors may encounter when seeking help, including from professionals.

We provide resources that others can use to alert others about IPV and stigma, including blog posts and other websites and resources that we share through social media. Specific groups that we have targeted in past resources include schools, churches, and college campuses.

We did a series on technology safety in partnership with the National Network to End Domestic Violence (See

http://www.seethetriumph.org/collection-technology-safety.html).

We listen both virtually and face-to-face to various stakeholders, such as through dialogue on our social media platforms and conference presentations on the campaign.

We mobilize resources available to us as university professors to promote social change.

We express ongoing appreciation for our partners' and contributors' contributions and strengths, as well as the unique perspectives they bring to the campaign.

As counselors and researchers, we are particularly equipped to address mental health-related issues, such as a recent blog post on suggestions for survivors on how to select a counselor.

We assess our impact through both informal (e.g., feedback received) and formal (e.g., tracking the growth in numbers of supporters) actions. Additional outcome evaluation work is planned as part of the future growth of the campaign.

As one example, we did a recent series on the stigma surrounding IPV in churches and focused on environmental strengths and challenges in those environments.

The research basis for the campaign provides data to support the need for our work.

The Delphi study we recently completed sought input from an expert panel to identify strategies for ending IPV-related stigma.

Our research asked survivors to describe specific sources of stigma they encountered, and their stories are highlighted through blogging and research articles. 
26. Develop a step-by-step plan for implementing the change process.

27. Develop a plan for dealing with probable responses to change; 28. Recognize and deal with resistance.

29. Assess the effect of counselor's advocacy efforts on the system and constituents.

Public Information

30. Recognize the impact of oppression and other barriers to healthy development.

31. Identify environmental factors that are protective of healthy development.

32. Prepare written and multi-media materials that provide clear explanations of the role of specific environmental factors in human development.

33. Communicate information in ways that are ethical and appropriate for the target population.

34. Disseminate information through a variety of media.

35. Identify and collaborate with other professionals who are involved in disseminating public information.

36. Assess the influence of public information efforts undertaken by the counselor. Social/Political Advocacy

37. Distinguish those problems that can best be resolved through social/political action.

38. Identify the appropriate mechanisms and avenues for addressing these problems.

39. Seek out and join with potential allies.

40. Support existing alliances for change.

41. With allies, prepare convincing data and rationales for change. 42. With allies, lobby legislators and
For each year the campaign is in existence, we develop a Master Plan for the year to guide our decisions and growth during the year.

A major challenge is ensuring that this advocacy work is recognized and supportive within our jobs as professors. As such, we ensure that we communicate with our colleagues and supervisors about our work and ground it clearly in our identities as counselors.

We monitor the traffic to our website/blog and social media platforms to identify the types of resources and blog posts that are of greatest interest to our community.

We view stigma as an oppressive force that presents challenges to survivors of IPV.

Through our social media initiatives, we aim to build a supportive, engaging community for survivors and other supporters.

We develop our own multi-media resources, as well as share highquality resources developed by other credible organizations.

We emphasize that survivors are in the best position to make decisions for themselves through blog posts and other communications.

We use multiple social media platforms to reach different audiences. Several of our See the Triumph blog posts have been re-posted elsewhere, such as on the Stop Abuse Campaign blog.

We track engagement with each piece of information we share through Facebook (e.g., number of likes, shares, and comments).

We believe that broad-based social action is required to end the stigma surrounding IPV. The burden to end this stigma should not fall solely on survivors. Thus, resources disseminated through the campaign are designed to reach survivors, professionals, and other members of the general population who may have opportunities to engage in advocacy efforts to end this stigma.

Although most of our past efforts have involved social media channels, we have begun to develop new resources that are designed for use in face-to-face contexts, such as workbooks to be used in discussion groups and curricula for arts-based workshops and a survivor advocacy training program.

We have grown a team of dedicated Contributors who share blog posts and other resources with us on a regular basis.

We highlight the works of others that address the stigma surrounding IPV. For example, we invite guest blogs from individuals working in other organizations (e.g., Change Purse for a guest blog on trafficking).

The Delphi study provided data on the scope of stigma and action steps needed to end it.

To date, our focus has been primarily on organizational-level policies, 


\begin{tabular}{|l|l|}
\hline other policy makers. & $\begin{array}{l}\text { such as our recent focus on churches and an upcoming series on } \\
\text { workplace policies. }\end{array}$ \\
\hline $\begin{array}{l}\text { 43. Maintain open dialogue with } \\
\text { communities and clients to ensure } \\
\text { that the social/political advocacy is } \\
\text { consistent with the initial goals. }\end{array}$ & $\begin{array}{l}\text { We maintain ongoing internal and external dialogue to ensure that we } \\
\text { focus on two main goals of developing resources for survivors and } \\
\text { ending the stigma surrounding IPV. }\end{array}$ \\
\hline
\end{tabular}

Note. Competencies are quoted directly from the ACA Advocacy Competencies (Lewis et al., 2002).

\section{Advocacy Lessons Learned through See the Triumph}

Our work with See the Triumph has presented many challenges, opportunities, and valuable lessons, both personally and professionally. In this section, we review some of the most significant lessons we have learned through this campaign, especially as they relate to our role as counselors and counselor educators engaging in advocacy work. Readers who are interested in learning more specific details about any aspect of the campaign are invited to contact its co-founders via the Contact Form on our website: http://www.seethetriumph.org/contact-us.html.

\section{Lesson 1: Sometimes You Seek Out Advocacy, Sometimes It Finds You}

When we began our line of research on the stigma surrounding IPV, we had no intention of using it to inform a social media campaign. We were initially drawn to the subject as an extension of our research, and even when we first began the campaign, we viewed it primarily as a tool for disseminating the findings of our research. However, the further along we progressed in the campaign, the more we embraced the role of advocates for social change, as we could increasingly see the potential impact of the social media initiatives for promoting positive social change. Given the depth of the experiences that the survivors who participated in our research shared, we felt a deep sense of moral and ethical responsibility to "do something about it." Morphing into the advocacy role became an exciting and rewarding opportunity for personal and professional growth that we had not anticipated at the start of our collaboration on our research.

\section{Lesson \#2: Partnerships are Critical for Success}

Given our minimal knowledge of social media marketing when we launched See the Triumph, we didn't recognize many of the skills and insights we did not yet have but needed to develop quickly for the campaign to get off the ground. As such, partnerships were critical to the successful growth of the campaign, and we do not believe we could have achieved the growth we experienced without the partnerships we forged. In particular, the mentoring that we received from the Stop Abuse Campaign was instrumental to developing the skills and knowledge we needed to run and grow the campaign. In addition, the other partnerships that we have forged over time each added several layers of value to our overall work. We value the new perspectives, skills, and ideas that new partners bring to the campaign so much that we maintain an ongoing focus on growing, nurturing, and developing these partnerships, both with individuals (e.g., guest bloggers) and organizations.

\section{Lesson \#3: Large-scale Advocacy Efforts Require Substantial Time and Effort}


Certainly, there are smaller-scale advocacy activities that counselors can carry out to promote positive change, such as writing a Letter to the Editor or helping a client connect with a needed community resource. However, larger-scale, ongoing initiatives_such as the See the Triumph campaign-require a substantial investment of time, energy, and other resources. Particularly in the realm of social media, initiatives require an ongoing flow of information and new resources in order to remain current. Therefore, we post and otherwise engage in our social media communities on nearly a daily basis, sometimes multiple times a day. We use a schedule to ensure that this happens in an organized manner. Thus, managing the initiative requires both advanced planning and daily efforts to ensure that our platforms are updated enough to stay current and relevant. Other time commitments include maintaining communications with partners, planning meetings, writing blog posts, developing infographics, and identifying relevant content from other organizations to share through our platforms. Given the substantial resources required to sustain this type of advocacy initiative, we believe it is important that advocacy is viewed as central to one's professional identity as a counselor and/or counselor educator. In contrast, if advocacy was viewed as an afterthought, it would likely be very difficult to commit the sufficient time, energy, and other resources to effectively carry out such an ongoing campaign.

\section{Lesson \#4: Advocacy May Not Fit Initially in Counselors' Job Duties, So They May Need to Advocate for Themselves to be Able to Do This Work}

Counselors and counselor educators may need to engage in self-advocacy to ensure that their advocacy efforts are recognized and valued within their work settings. For example, practicing counselors in agencies may not initially have organizational support to take time away from providing billable counseling services. In our cases, as counselor educators and professors, advocacy work does not neatly fall within the typical domains of professors' roles: research, teaching, and service. Research dissemination activities beyond publishing in peer-reviewed journals are often not valued as highly in university promotion and tenure guidelines (Murray, Smith, \& Avent, 2010). Further, service activities within an academic context often refer to more formal roles, such as professional leadership or committees at the professional or university levels. Therefore, as the See the Triumph campaign has taken up a greater amount of our time and attention, we have taken steps to ensure that this nontraditional work for us as academics is supported. First, we maintain communication about the campaign with our Department Chairs to keep them informed of our work. Second, we ground our advocacy work in the more traditionally-valued roles within academia. In particular, the See the Triumph campaign not only grew out of research studies, but we maintain an ongoing program of research related to the campaign and publish findings in traditional peer-reviewed journals. We have involved graduate students from our respective counseling programs in the project, so that students are aware of the campaign and can become involved. In addition, we have been intentional about demonstrating the links between the campaign and our research, such as by providing channels for study participant recruitment and by providing us with an ongoing source of new ideas and information that lead to new research and service ventures. Overall, although we personally understand the inherent value in working on the See the Triumph campaign, we maintain a focus on ensuring that this work is also valued and supported within our broader work contexts. This support is critical to being able to sustain the initiative over time. 


\section{Lesson \#5: Advocacy Involves Exposing Oneself to New Forms of Vulnerabilities}

Similar to Lesson \#4, engaging in advocacy work has provided personal challenges resulting from stepping outside of the traditional types of work in which we engage as professors. Despite its frustrations, there is a certain level of comfort that results from the extensive peer-review process of scholarly journals. Once ideas are published, they have been thoroughly vetted by reviewers and editors, and the review process itself provides some level of validation that the ideas expressed in a manuscript hold value for the broader audience. When we moved into the realm of blogging, we initially treaded lightly, as the process led to feelings of vulnerability and being exposed. Our early blogs were very brief and provided little additional information beyond summarizing and quoting participants in our research. Even these early blogs were initially somewhat uncomfortable to write and post-the blogging forum made our thoughts and ideas very open and immediately available for comment and reaction, whether positive or negative. Further, by posting publicly on-line, the potential audience was much wider, and anything posted there could realistically last indefinitely. Even if we were to remove a particular post for any reason, it would have been possible for someone else to copy it and re-post it elsewhere. To both of us, as trained academics, this felt like a risky proposition. However, as our audience grew and our advocacy identity solidified, we began to realize the numerous potential rewards that accompanied the risks. As such, we embarked to learn more about blogging. One source, the Huffington Post Complete Guide to Blogging (Huffington Post Editors, 2008), encouraged us to view blogging as a forum for sharing ideas that were works-in-progress, which freed us to view this process as more open and developmental, and as part of a larger social dialogue. As we've expanded our blogging focus, some of those initial feelings of vulnerability remain, but now we welcome the opportunity for immediate feedback and dialogue as exciting and essential for the continued growth of the campaign.

\section{Lesson \#6: Change is Slow}

If we could, we would not only end the stigma surrounding IPV tomorrow, if not today, but we would also end IPV altogether right now. However, we are mindful that the issues we are addressing-IPV and the stigma surrounding it-are deeply embedded into our culture and many social systems within the broader culture. The type of change we aim to promote is likely to take generations to manifest, and therefore we must remain mindful of the relatively small triumphs that occur along the way. Put simply, if we were to hope for an immediate end to IPV and stigma, we would surely lose hope and give up easily. Rather, we must take the long-range view and remain focused on the longterm goal, while also taking action on a daily basis to work toward the longer-term change. To help manage the potential frustrations of waiting for such large-scale changes, we actively focus on appreciating the smaller steps along the way. For example, each new "Like" on our Facebook page represents another person who is interested in partnering with us to work toward social change. We celebrate the growth and development of the campaign, not just because it shows that we are reaching a wider audience, but even more because that growth signifies stronger and greater partnerships to end the stigma surrounding IPV and provide support to survivors. 


\section{Lesson \#7: Counselors Have a Unique, Valuable Role to Play in Advocacy Work}

The final lesson we have learned is the value of counselors' unique perspectives on social issues. Certainly, there are many professional and grassroots groups working to address IPV, including victim advocates, advocacy groups, and law enforcement officials. Counselors can bring a unique vantage point for understanding and addressing IPV at an individual level and in society. Counselors, whether through practice or research, are entrusted with people's stories and experiences in a way that other professionals often do not have the ability to access. Of course, counselors must honor clients' and study participants' confidentiality and other ethical privileges and rights. However, counselors also have opportunities, when appropriate, to help clients tell their stories in ways that are safe, meaningful, and able to help promote positive social change. When clients want to share their stories but may not feel safe or comfortable to do so on their own, counselors can give voice to those stories and ensure that clients' experiences help to inform the social dialogue surrounding important issues, such as IPV.

\section{Conclusions}

Advocacy is growing increasingly important and central to the counseling profession. However, given the lack of training in this area that many counselors receive, it is likely that many counselors feel uncomfortable taking on advocacy efforts. Indeed, that was the case for us early in the development of the See the Triumph campaign. The ACA Advocacy Competencies (Lewis et al., 2002) offer a meaningful framework to guide counselors' work in this area. In this article, we reviewed how these Competencies provided a framework for our work through See the Triumph, offering counselors and counselor educators one example of advocacy in action. However, we encourage readers to view the examples we provided as a starting point for considering ways to integrate advocacy into their own work. Advocacy efforts must be shaped by the goals of the initiatives, the needs and characteristics of the client populations and social systems that counselors aim to address, and the strengths, resources and passions of the advocates. Overall, advocacy work presents counselors with many opportunities to expand the influence of their work and promote positive change in the larger environment. By putting the ACA Advocacy Competencies into practice, counselors can advance the counseling profession's ability to make positive differences in the lives of the clients we serve.

\section{Author Contact Information}

Correspondence regarding this article should be directed to: Christine E. Murray, UNCG Department of Counseling and Educational Development, 221 Curry Building, Greensboro, NC 27402. Email: cemurray@uncg.edu

Christine E. Murray, PhD, LPC, LMFT, is an associate professor in the Department of Counseling and Educational Development at the University of North Carolina at Greensboro. Allison Crowe, PhD, LPC, NCC, is an assistant professor of Counselor Education at East Carolina University in the Department of Interdisciplinary Professions. Drs. Murray and Crowe are the Co-Founders of See the Triumph (www.seethetriumph.org). 


\section{References}

Crowe, A., \& Murray, C. E. (2015). Stigma from professional helpers toward survivors of intimate partner violence. Partner Abuse, 6(2), 157-179.

Esqueda, C. W., \& Harrison, L. A. (2005). The influence of gender role stereotypes, the woman's race, and level of provocation and resistance on domestic violence culpability attributions. Sex Roles, 53, 821-835.

Fitzpatrick, M. K., Salgado, D. M., Suvak, M. K., King, L. A., \& King, D. W. (2004). Association of gender and gender-role ideology with behavioral and attitudinal features of intimate partner aggression. Psychology of Men \& Masculinity, 5, 91-102.

Flasch, P. Murray, C. E., \& Crowe, A. (in press) Overcoming abuse: A phenomenological investigation of the journey to recovery from past intimate partner violence. Journal of Interpersonal Violence.

Retrieved from http://jiv.sagepub.com/content/early/2015/08/07/0886260515599161.full.pdf?ijkey=QRA1eva olYzWd7Y\&keytype=finite.

Huffington Post Editors (2008). The Huffington Post complete guide to blogging. New York: Simon \& Schuster.

Langhinrichsen-Rohling, J., Shlien-Dellinger, R. K., Huss, M. T., \& Kramer, V. L. (2004). Attributions about perpetrators and victims of interpersonal abuse. Journal of Interpersonal Violence, 19, 484-498.

Lewis, J. A., Arnold, M. S., House, R., \& Toporek, R. L. (2002). ACA Advocacy Competencies. Retrieved from http://www.counseling.org/docs/competencies/advocacy_competencies.pdf?sfvrsn=3.

Murray, C. E. (2009). Diffusion of innovation theory: A framework for bridging the research-practice gap in counseling. Journal of Counseling and Development, 87, 108-116.

Murray, C. E., Crowe, A., \& Akers, W. (2016). How can we end the stigma surrounding domestic and sexual violence? A modified Delphi study with national advocacy leaders. Journal of Family Violence, 31(3), 271-287. DOI: 10.1007/s10896-015-9768-9.

Murray, C. E., Crowe, A., \& Brinkley, J. (2015). The stigma surrounding intimate partner violence: A cluster analysis study. Partner Abuse, 6, 320-336.

Murray, C. E., Crowe, A., \& Overstreet, N. (in press). Sources and components of stigma experienced by survivors of intimate partner violence. Journal of Interpersonal Violence.

Murray, C. E., King, K., Crowe, A., \& Flasch, P. (2015). Survivors of intimate partner violence as advocates for social change. Journal of Social Action in Counseling and Psychology, 7, 84-100. Retrieved September 11, 2015, from http://www.psysr.org/jsacp/murray-v7n1-2015_84-100.pdf.

Murray, C. E., Smith, P. H., \& Avent, J. (2010). Solutions to the research-practice gap in domestic violence: A modified Delphi study with domestic violence coalition leaders. Journal of Aggression, Maltreatment, and Trauma, 19(4), 424-449.

Murray, C. E., \& Welch, M. (2010). Preliminary construction of a service provider-informed domestic violence research agenda. Journal of Interpersonal Violence, 25(12), 2279-2296. DOI: $10.1177 / 0886260509354883$.

Overstreet, N. M., \& Quinn, D. M. (2013). The intimate partner violence stigmatization model and barriers to help seeking. Basic and Applied Social Psychology, 35, 109-122. 
Steele, J. M. (2008). Preparing counselors to advocate for social justice: A Liberation Model. Counselor Education and Supervision, 48, 74-85.

Toporek, R. L., Lewis, J. \& Crethar, H. C. (2009). Promoting systemic change through the Advocacy Competencies. Special Section on ACA Advocacy Competencies. Journal of Counseling and Development, 87, 260-268.

Yamawaki, N., Ostenson, J., \& Brown, C. R. (2009). The functions of gender role traditionality, ambivalent sexism, injury, and frequency of assault on domestic violence perception: A study between Japanese and American college students. Violence Against Women, 15, 1126-1142. doi:10.1177/1077801209340758

U.S. Centers for Disease Control and Prevention (2011). The Health Communicator's Social Media Toolkit, Retrieved from

http://www.cdc.gov/socialmedia/tools/guidelines/pdf/socialmediatoolkit_bm.pdf. 